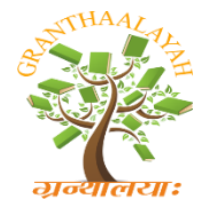
\author{
GRANTHAALAYAH \\ A knowledge Repository
}

INTERNATIONAL JOURNAL OF RESEARCH -

Science

\title{
AGRICULTURAL REVOLUTION IN THE LINE OF HUMAN EVOLUTION IS THE ONSET OF NUTRITIONAL METABOLIC DISEASES, EPIDEMIC OF CANCER AND THE INFECTIOUS DISEASES
}

\author{
Somayeh Zaminpira ${ }^{* 1}$, Sorush Niknamian ${ }^{2}$ \\ ${ }^{* 1}$ Ph.D. in Cellular and Molecular Biology, University of Cambridge, United Kingdom \\ ${ }^{2}$ Ph.D. in Cellular and Molecular Biology, University of Cambridge, United Kingdom
}

DOI: https://doi.org/10.29121/granthaalayah.v5.i3.2017.1757

\begin{abstract}
This study goes deeply through the nutrition of the first primate and analyses the nutrition in the line of human evolution. Simply dividing the shifts in the nutrition through the human evolution, it is obvious that some elements in the diet are more important than the others. Since the beginning of the Neolithic, the ratio of plant-to-animal foods in the diet has sharply increased from an average of probably $65 \%$ to $35 \%$ during Paleolithic times to as high as $90 \%$ to $10 \%$ since the advent of agriculture. The changes in diet from hunter-gatherer times to agricultural times have been almost all detrimental, although there is some evidence indicating that at least some genetic adaptation to the Neolithic has begun taking place in the approximately 10,000 years since it began. With the much heavier reliance on starchy foods that became the staples of the diet, tooth decay, malnutrition, and rates of infectious disease increased dramatically over Paleolithic times, further exacerbated by crowding leading to even higher rates of communicable infections. This evidences shows that the immune system of human beings became weaker and many metabolic diseases including cancer has become epidemic. The height of humans has decreased in the agricultural revolution as well.
\end{abstract}

Keywords: Neolithic; Paleolithic; Metabolic Diseases; Infectious Diseases; Cancer.

Cite This Article: Somayeh Zaminpira, and Sorush Niknamian. (2017). "AGRICULTURAL REVOLUTION IN THE LINE OF HUMAN EVOLUTION IS THE ONSET OF NUTRITIONAL METABOLIC DISEASES, EPIDEMIC OF CANCER AND THE INFECTIOUS DISEASES." International Journal of Research - Granthaalayah, 5(3), 88-103. https://doi.org/10.29121/granthaalayah.v5.i3.2017.1757.

\section{Introduction}

Human evolution is the evolutionary process that led to the emergence of anatomically modern humans. Human evolution typically focuses on the evolutionary history of the primates and in particular the genus Homo, and the emergence of Homo sapiens as a distinct species of the 
hominids or great apes rather than studying the earlier history that led to the primates. The study of human evolution involves many scientific disciplines, including physical anthropology, primatology, archaeology, paleontology, neurobiology, ethology, linguistics, evolutionary psychology, embryology and genetics.[103] Genetic researches show that primates diverged from other mammals about 85 million years ago, in the Late Cretaceous period, and the earliest fossils appear in the Paleocene, around 55 million years ago.[104] Within the Hominoidea or simply, apes superfamily, the Hominidae family diverged from the Hylobatidae that is gibbon family some 15 to 20 million years ago. African great apes which are subfamily Homininae, diverged from orangutans or Ponginae about 14 million years ago. The Hominini tribe that is humans, Australopithecines and other extinct biped genera, and chimpanzees, parted from the Gorillini tribe between 9 million years ago and 8 million years ago, and in turn, the subtribes Hominina and Panina or chimps, separated about 7.5 million to 5.6 million years ago.[105]

The basic adaptation of the hominin line is bipedalism. The earliest bipedal hominin is considered to be either Sahelanthropus or Orrorin, alternatively, either Sahelanthropus or Orrorin may instead be the last shared ancestor between chimps and humans. Ardipithecus, a full biped, arose somewhat later, and the early bipeds eventually evolved into the australopithecines, and later into the genus Homo. The earliest documented representative of the genus Homo is Homo habilis, which evolved around 2.8 million years ago,[106] and is arguably the earliest species for which there is positive evidence of the use of stone tools. The brains of these early hominins were about the same size as that of a chimpanzee, although it has been suggested that this was the time in which the human SRGAP2 gene doubled, producing a more rapid wiring of the frontal cortex. During the next million years a process of rapid encephalization occurred, and with the arrival of Homo erectus and Homo ergaster in the fossil record, cranial capacity had doubled to $850 \mathrm{~cm}^{3}$.[107] Such an increase in human brain size is equivalent to each generation having 125,000 more neurons than their parents. It is believed that Homo erectus and Homo ergaster were the first to use fire and complex tools, and were the first of the hominin line to leave Africa, spreading throughout Africa, Asia, and Europe between 1.3 to 1.8 million years ago.

According to the recent African origin of modern humans theory, modern humans evolved in Africa possibly from Homo heidelbergensis, Homo rhodesiensis or Homo antecessor and migrated out of the continent some 50,000 to 100,000 years ago, gradually replacing local populations of Homo erectus, Denisova hominins, Homo floresiensis and Homo neanderthalensis.[108][109][110][111][112] Archaic Homo sapiens, evolved in the Middle Paleolithic between 400,000 and 250,000 years ago.[113][114][115] The DNA evidence suggests that several haplotypes of Neanderthal origin are present among all non-African populations, and Neanderthals and other hominins, such as Denisovans, may have contributed up to $6 \%$ of their genome to present-day humans, suggestive of a limited inter-breeding between these species.[116][117][118] The transition to behavioral modernity with the development of symbolic culture, language, and specialized lithic technology happened around 50,000 years ago.[119][120][121] 


\section{Materials and Methods}

\section{$65,000,000$ to $50,000,000$ B.C.}

The first primates, resembling today's mouse lemurs, bush-babies, and tarsiers, weighing in at 2 lbs. or less, and eating a largely insectivorous diet.[1]

\section{$50,000,000$ to 30,000,000 B.C.}

A gradual shift in diet for these primates to mostly frugivorous in the middle of this period to mostly herbivorous towards the end of it, but with considerable variance between specific primate species as to lesser items in the diet, such as insects, meat, and other plant foods.[2]

$30,000,000$ to $10,000,000$ B.C.

Fairly stable persistence of above dietary pattern.[3]

\section{$10,000,000$ to $7,000,000$ B.C.}

Last common primate ancestor of both humans and the modern ape family. [4]

\section{7,000,000 to 5,000,000 B.C.}

After the end of the previous period, a fork occurs branching into separate primate lines, including humans. [5] The DNA evidence shows that humans are closely related to both gorillas and chimpanzees, but most closely to the chimp. [6] Most paleoanthropologists believe that after the split, flesh foods began to assume a greater role in the human side of the primate family at this time. [7]

\section{4,500,000 B.C.}

First known hominid or proto-human from fossil remains, known as Ardipithecus ramidus literally translating as root ape for its position as the very first known hominid, which may not yet have been fully bipedal that is walking upright on two legs. Anatomy and dentition or teeth are very suggestive of a form similar to that of modern chimpanzees. [8]

\section{3,700,000 B.C.}

First fully upright bipedal hominid, Australopithecus afarensis meaning southern ape, for the initial discovery in southern Africa, about 4 feet tall, first known popularly from the famous Lucy skeleton. [9]

\section{$3,000,000$ to $2,000,000$ B.C.}

Australopithecus line diverges into sub-lines, [10] one of which will eventually give rise to Homo sapiens or modern man. It appears that the environmental impetus for this adaptive radiation into different species was a changing global climate between 2.5 and 2 million years ago driven by glaciation in the Polar Regions. [11] The climatic repercussions in Africa resulted in a breakup of the formerly extensively forested habitat into a mosaic of forest interspersed with savanna or grassland. This put stress on many species to adapt to differing conditions and availability of foodstuffs. [12] The different Australopithecus lineages, thus, ate somewhat differing diets, ranging from more herbivorous meaning high in plant matter to more frugivorous or higher in soft and/or hard fruits than in other plant parts. There is still some debate as to which Australopithecus lineage modern humans ultimately descended from, but recent evidence based 
on strontium/calcium ratios in bone, plus teeth microwear studies, show that whatever the lineage, some meat was eaten in addition to the plant foods and fruits which were the staples.[13]

\section{$2,300,000$ to $1,500,000$ B.C.}

Appearance of the first true humans signified by the genus Homo, known as Homo habilis or handy man so named because of the appearance of stone tools and cultures at this time. These gatherer-hunters were between 4 and 5 feet in height, weighed between 40 to 100 pounds, and still retained tree-climbing adaptations such as curved finger bones [14] while subsisting on wild plant foods and scavenging and/or hunting meat. The evidence for flesh consumption based on cut-marks on animal bones, as well as use of hammerstones to smash them for the marrow inside, dates to this period.[15] It is thought that they lived in small groups like modern huntergatherers but that the social structure would have been more like that of chimpanzees.[16]

The main controversy about this time period by paleoanthropologists is not whether Homo habilis consumed flesh which is well established, but whether the flesh they consumed was primarily obtained by scavenging kills made by other predators or by hunting.[17] The latter would indicate a more developed culture, the former a more primitive one. While meat was becoming a more important part of the diet at this time, based on the fact that the diet of modern hunter-gatherers with their considerably advanced tool set has not been known to exceed $40 \%$ meat in tropical habitats like habilis evolved in, we can safely assume that the meat in habilis diet would have been substantially less than that. [18]

\section{$1,700,000$ to 230,000 B.C.}

Evolution of Homo habilis into the erectines, which is a range of human species often collectively referred to as Homo erectus, after the most well-known variant. Similar in height to modern humans that is 5-6 feet, but stockier with a smaller brain, hunting activity increased over habilis, so that meat in the diet assumed greater importance. Teeth microwear studies of erectus specimens have indicated harsh wear patterns typical of meat-eating animals like the hyena. [19] No text we have yet read ventures any sort of percentage figure from this time period, but it is commonly acknowledged that plants still made up the largest portion of the subsistence. More typically human social structures made their appearance with the erectines as well. [20]

The erectines were the first human ancestor to control and use fire. It is thought that perhaps because of this, but more importantly because of other converging factors such as increased hunting and technological sophistication with tools that about 900,000 years ago in response to another peak of glacial activity and global cooling which broke up the tropical landscape further into an even patchier mosaic, the erectines were forced to adapt to an increasingly varied savanna/forest environment by being able to alternate opportunistically between vegetable and animal foods to survive, and/or move around nomadically.[21] For whatever reasons, it was also around this time dated to approx. 700,000 years ago, that a significant increase in large land animals occurred in Europe, elephants, hoofed animals, hippopotamuses, and predators of the big-cat family, as these animals spread from their African home. It is unlikely to have been an accident that the spread of the erectines to the European and Asian continent during and after this timeframe coincides with this increase in game as well, as they probably followed them.[22] Because of the considerably harsher conditions and seasonal variation in food supply, hunting became more important to bridge the seasonal gaps, as well as the ability to store nonperishable 
items such as nuts, bulbs, and tubers for the winter when the edible plants withered in the autumn. All of these factors, along with clothing and also perhaps fire, helped enable colonization of the less hospitable environment. There were also physical changes in response to the colder and darker areas that were inhabited, such as the development of lighter skin color that allowed the sun to penetrate the skin and produce vitamin D, as well as the adaptation of the fat layer and sweat glands to the new climate.[23] Erectus finds from northern China 400,000 years ago have indicated an omnivorous diet of meats, wild fruit and berries including hackberries, plus shoots and tubers, and various other animal foods such as birds and their eggs, insects, reptiles, rats, and large mammals.[24]

\section{0,000 to 200,000 B.C.}

Archaic Homo sapiens, our immediate predecessor, appears. These human species, of which there were a number of variants, did not last as long in evolutionary time as previous ones, apparently due simply to the increasingly rapid rate of evolution occurring in the human line at this time. Thus they represent a transitional time after the erectines leading up to modern man, and the later forms are sometimes not treated separately from the earliest modern forms of true Homo sapiens. [25]

\section{0,000 to 120,000 B.C.}

Homo sapiens neanderthalensis or the Neanderthals, begin appearing in Europe, reaching a height between 90,000 and 35,000 years ago before becoming extinct. It is now well accepted that the Neanderthals were an evolutionary offshoot that met an eventual dead-end. In other words, they were not our ancestors, and that more than likely, both modern Homo sapiens and Neanderthals were sister species descended from a prior common archaic sapiens ancestor. [26]

\section{0,000 to 110,000 B.C.}

First appearance of anatomically modern humans or Homo sapiens. [27] The last Ice Age also dates from this period, stretching from 115,000 to 10,000 years ago. Thus it was in this context, which included harsh and rapid climatic changes that our most recent ancestors had to flexibly adapt their eating and subsistence. [28] Climatic shifts necessitating adaptations were also experienced in tropical regions, though to a lesser degree. [29] It may therefore be significant that fire, though discovered earlier, came into widespread use around this same time [30] corresponding with the advent of modern human beings. Its use may in fact be a defining characteristic of modern humans and their mode of subsistence. [31]

\section{0,000 to 120,000 B.C.}

Some of the earliest evidence for sea-foods or molluscs, primarily in the diet by coastal dwellers appears at this time [32], although in one isolated location discovered, there is evidence going back 300,000 years ago. [33] Common use of sea-foods by coastal aborigines becomes evident about 35,000 years ago, [34] but widespread global use in the fossil record is not seen until around 20,000 years ago and since. [35] For the most part, sea-foods should probably not be considered a major departure; however, as the composition of fish, shellfish, and poultry more closely resembles the wild land-game animals many of these same ancestors ate than any other source today except for commercial game farms that attempt to mimic ancient meat. [36] 


\section{0,000 to 35,000 B.C.}

The first behaviorally modern human beings as seen in the sudden explosion of new forms of stone and bone tools, cave paintings and other artwork, plus elaborate burials and many other quintessentially modern human behaviors. The impetus or origin for this watershed event is still a mystery. [37]

\section{0,000 B.C. to 10-8,000 B.C.}

Last period prior to the advent of agriculture in which human beings universally subsisted by hunting and gathering, also known as the Late Paleolithic or Stone Age-period. Paleolithic people did process some of their foods, but these were simple methods that would have been confined to pounding, grinding, scraping, roasting, and baking. [38]

\section{5,000 B.C. to 15-10,000 B.C.}

The Cro-Magnons or fully modern pre-Europeans, thrive in the cold climate of Europe via biggame hunting, with meat consumption rising to as much as $50 \%$ of the diet. [39]

\section{5,000 to 15,000 B.C.}

Coldest period of the last Ice Age, during which global temperatures averaged $14^{\circ} \mathrm{F}$ cooler than they do today [40] with local variations as much as $59^{\circ} \mathrm{F}$ lower [41], with an increasingly arid environment and much more difficult conditions of survival to which plants, animals, and humans all had to adapt. [42] The Eurasian steppes just before and during this time had a maximum annual summer temperature of only $59^{\circ} \mathrm{F}$. [43]

Humans in Europe and northern Asia, and later in North America, adapted by increasing their hunting of the large mammals such as mammoths, horses, bison and caribou which flourished on the open grasslands, tundra, and steppes which spread during this period. [44] Storage of vegetable foods that could be consumed during the harsh winters was also exploited. Clothing methods were improved, including needles with eyes and sturdier shelters developed, the most common being animal hides wrapped around wooden posts, some of which had sunken floors and hearths. [45] In the tropics, large areas became arid. In South Africa, for instance, the vegetation consisted mostly of shrubs and grass with few fruits. [46]

\section{0,000 B.C. to 9,000 B.C.}

Transitional period known as the Mesolithic, during which the bow-and-arrow appeared, [47] and gazelle, antelope, and deer were being intensively hunted, [48] while at the same time precursor forms of wild plant and game management began to be more intensively practiced. At this time, wild grains, including wheat and barley by 17,000 B.C., before their domestication, were being gathered and ground into flour as evidenced by the use of mortars-and-pestles in what is now modern-day Israel. By 13,000 B.C. the descendants of these peoples were harvesting wild grains intensely and it was only a small step from there to the development of agriculture. [49] Game management through the burning-off of land to encourage grasslands and the increase of herds became widely practiced during this time as well. In North America, for example, the western high plains are the only area of the current United States that did not see intensive changes to the land through extensive use of fire. [50] 
Also during this time, and probably also for some millennia prior to the Mesolithic, perhaps as early as 45,000 B.C., ritual and magico-religious sanctions protecting certain wild plants developed, initiating a new symbiotic relationship between people and their food sources that became encoded culturally and constituted the first phase of domestication well prior to actual cultivation. Protections were accorded to certain wild food species yams being a well-known example to prevent disruption of their life cycle at periods critical to their growth, so that they could be profitably harvested later. [51] Digging sticks for yams have also been found dating to at least 40,000 B.C., [52] so these tubers considerably antedated the use of grains in the diet. Foods known to be gathered during the Mesolithic period in the Middle East were root vegetables, wild pulses, peas, beans, etc., nuts such as almonds, pistachios, and hazelnuts, as well as fruits such as apples. Sea-foods such as fish, crabs, mollusks, and snails also became common during this time. [53]

\section{0,000 B.C.}

The beginning of the Neolithic period, or Agricultural Revolution, that means farming and animal husbandry. The transition to agriculture was made necessary by gradually increasing population pressures due to the success of Homo sapiens prior hunting and gathering way of life. Hunting and gathering can support perhaps one person per square 10 miles, Neolithic agriculture 100 times or more that many. [54] Also, at about the time population pressures were increasing, the last Ice Age ended, and many species of large game became extinct, probably due to a combination of both intensive hunting and disappearance of their habitats when the Ice Age ended. [55] Wild grasses and cereals began flourishing, making them prime candidates for the staple foods to be domesticated, given our previous familiarity with them. [56] By 9,000 B.C. sheep and goats were being domesticated in the Near East, and cattle and pigs shortly after, while wheat, barley, and legumes were being cultivated somewhat before 7,000 B.C., as were fruits and nuts, while meat consumption fell enormously. [57] By 5,000 B.C. agriculture had spread to all inhabited continents except Australia. [58] During the time since the beginning of the Neolithic, the ratio of plant-to-animal foods in the diet has sharply increased from an average of probably $65 \%$ to $35 \%$ during Paleolithic times [59] to as high as $90 \%$ to $10 \%$ since the advent of agriculture. [60]

\section{Decrease in Health Status after the Neolithic}

The changes in diet from hunter-gatherer times to agricultural times have been almost all detrimental, although there is some evidence indicating that at least some genetic adaptation to the Neolithic has begun taking place in the approximately 10,000 years since it began. With the much heavier reliance on starchy foods that became the staples of the diet, tooth decay, malnutrition, and rates of infectious disease increased dramatically over Paleolithic times, further exacerbated by crowding leading to even higher rates of communicable infections. Skeletal remains show that height decreased by four inches from the Late Paleolithic to the early Neolithic, brought about by poorer nutrition, and perhaps also by increased infectious disease causing growth stress, and possibly by some inbreeding in communities that were isolated. Signs of osteoporosis and anemia, which was almost non-existent in pre-Neolithic times, have been frequently noted in skeletal pathologies observed in the Neolithic peoples of the Middle East. It is known that certain kinds of osteoporosis which have been found in these skeletal remains are caused by anemia, and although the causes have not yet been determined exactly, the primary 
suspect is reduced levels of iron thought to have been caused by the stress of infectious disease rather than dietary deficiency, although the latter remains a possibility. [61]

\section{Results and Discussions}

\section{Genetic Adaptation Time}

\section{Rates of genetic change from speciation}

The two sources for estimates of rates at which genetic change takes place are from students of the fossil record and from population geneticists. Where the fossil record is concerned, Niles Eldredge, along with Stephen Jay Gould, two of the most well-known modern evolutionary theorists, estimated the time span required for speciation events, the time required for a new species to arise in response to evolutionary selection pressures to be somewhere within the range of five to 50,000 years. [85] Since this rough figure is based on the fossil record, it makes it difficult to be much more precise than that range. Eldredge also comments that some evolutionary geneticists have said that the estimate of five to 50,000 years is, if anything, overly generous. [86] Also remember that this time span is for changes large enough to result in a new species classification. Since we are talking here about changes digestive changes that may or may not be large enough to result in a new species though changes in diet often are in fact behind the origin of new species, it's difficult to say from this particular estimate whether we may be talking about a somewhat shorter or longer time span than that for adaptation to changes in food.

\section{Measurements of genetic change from population genetics}

Fortunately, however, the estimates from the population geneticists are more precise. There are even mathematical equations to quantify the rates at which genetic change takes place in a population, given evolutionary "selection pressures" of a given magnitude that favor survival of those individuals with a certain genetic trait. [87] The difficulty lies in how accurately one can numerically quantify the intensity of real-world selection pressures. The most interesting of these examples relates directly to the title here, and has to do with the gene for lactose tolerance in adults. Babies are born with the capacity to digest lactose via production of the digestive enzyme lactase. Otherwise they wouldn't be able to make use of mother's milk, which contains the milk sugar lactose. But sometime after weaning, this capacity is normally lost, and there is a gene that is responsible. Most adults roughly $70 \%$ of the world's population overall - do not retain the ability to digest lactose into adulthood [88] and this outcome is known as "lactose intolerance. Actually this is something of a misnomer, since adult lactose intolerance would have been the baseline normal condition for virtually everyone in the human race up until Neolithic agricultural times.[89] If these people attempt to drink milk, then the result may be bloating, gas, intestinal distress, diarrhea, etc. [90]

\section{Influence of human culture on genetic selection pressures}

However those population groups that $d o$ retain the ability to produce lactase and digest milk into adulthood are those descended from the very people who first began domesticating animals for milking during the Neolithic period several thousand years ago. [91] The earliest milking 
populations in Europe, Asia, and Africa began the practice probably around 4,000 B.C. [92] And even more interestingly, in population groups where cultural changes have created "selection pressure" for adapting to certain behavior - such as drinking milk in this case - the rate of genetic adaptation to such changes significantly increases. In this case, the time span for widespread prevalence of the gene for lactose tolerance within milking population groups has been estimated at approximately 1,150 years [93] a very short span of time in evolutionary terms.

\section{Relationship between earliest milking cultures and prevalence of lactose tolerance in populations}

There is a very close correlation between the $30 \%$ of the world's population who are tolerant to lactose and the earliest human groups who began milking animals. These individuals are represented most among modern-day Mediterranean, East African, and Northern European groups, and emigrants from these groups to other countries. Only about $20 \%$ of white Americans in general are lactose intolerant, but among sub-groups the rates are higher: $90-100 \%$ among Asian-Americans as well as Asians worldwide, $75 \%$ of African-Americans (most of whom came from West Africa), and $80 \%$ of Native Americans. $50 \%$ of Hispanics worldwide are lactose intolerant. [94] Now whether it is still completely healthy for the $30 \%$ of the world's population who are lactose tolerant to be drinking animals' milk which is a very recent food in our evolutionary history. It may well be there are other factors involved in successfully digesting and making use of milk without health side-effects other than the ability to produce lactase.

\section{Genetic changes in population groups who crossed the threshold from hunting-gathering to grain-farming earliest}

Another interesting example of the spread of genetic adaptations since the Neolithic has been two specific genes whose prevalence has been found to correlate with the amount of time populations in different geographical regions have been eating the grain-based high-carbohydrate diets common since the transition from hunting and gathering to Neolithic agriculture began 10,000 years ago. These two genes are the gene for angiotensin-converting enzyme or ACE and the one for apolipoprotein B, which, if the proper forms are not present, may increase one's chances of getting cardiovascular disease. [95] In the Middle East and Europe, rates of these two genes are highest in populations (such as Greece, Italy, and France) closer to the Middle Eastern fertile crescent where agriculture in this part of the globe started, and lowest in areas furthest away, where the migrations of early Neolithic farmers with their grain-based diets took longest to reach that means Northern Ireland, Scotland, Finland, Siberia. Closely correlating with both the occurrence of these genes and the historical rate of grain consumption are corresponding rates of deaths due to coronary heart disease. Those in Mediterranean countries who have been eating high-carbohydrate grain-based diets the longest for example since approximately 6,000 B.C. in France and Italy, have the lowest rates of heart disease, while those in areas where dietary changes due to agriculture were last to take hold, such as Finland perhaps only since 2,000 B.C., have the highest rates of death due to heart attack. Statistics on breast cancer rates in Europe also are higher for countries that have been practicing agriculture the least amount of time. [96] 
Whether grain-based diets eaten by people whose ancestors only began doing so recently and therefore lack the appropriate gene is actually causing these health problems and not simply correlated by coincidence is at this point a hypothesis under study. One study with chickens, however who in their natural environment eat little grain has shown much less atherosclerosis on a high-fat, high-protein diet than on a low-fat, and high-carbohydrate diet. [97] But again, and importantly, the key point here is that genetic changes in response to diet can be more rapid than perhaps once thought. The difference in time since the advent of Neolithic agriculture between countries with the highest and lowest incidences of these two genes is something on the order of 3,000-5,000 years, [98] showing again that genetic changes due to cultural selection pressures for diet can force more rapid changes than might occur otherwise.

\section{Evolutionary changes in immunoglobulin types and genetic rates of change overall}

Now we should also look at the other end of the time scale for some perspective. The CavalliSforza population genetics team that has been one of the pioneers in tracking the spread of genes around the world due to migrations and/or interbreeding of populations has also looked into the genes that control immunoglobulin types an important component of the immune system. Their estimate here is that the current variants of these genes were selected for within the last 50,000100,000 years, and that this time span would be more representative for most groups of genes. They also feel that in general it is unlikely gene frequencies for most groups of genes would undergo significant changes in time spans of less than about 11,500 years. [99]

However, the significant exception they mention is where there are cultural pressures for certain behaviors that affect survival rates. [100] And the two examples cited above: the gene for lactose tolerance and those genes associated with high-carbohydrate grain consumption, both involve cultural selection pressures that came with the change from hunting and gathering to Neolithic agriculture. Again, cultural selection pressures for genetic changes operate more rapidly than any other kind. Nobody yet, really knows whether or not the observed genetic changes relating to the spread of milk-drinking and grain-consumption are enough to confer a reasonable level of adaptation to these foods among populations who have the genetic changes, and the picture seems mixed.

\section{Rates of gluten intolerance}

Rates of gluten intolerance are lower than for lactose intolerance, which one would expect given that milk-drinking has been around for less than half the time grain-consumption has. Official estimates of gluten intolerance range from $0.3 \%$ to $1 \%$ worldwide depending on population group. [101] Some researchers, however, believe that gluten intolerance is but the tip of the iceberg of problems due to grain consumption or more specifically, wheat. Newer research seems to suggest that anywhere from $5 \%$ to as much as $20-30 \%$ of the population with certain genetic characteristics (resulting in what is called a "permeable intestine") may absorb incompletely digested peptide fragments from wheat with adverse effects that could lead to a range of possible diseases. [102] 


\section{Diet of chimpanzees}

Most populations of chimpanzees are getting somewhere in the neighborhood of $5 \%$ of their diet on average in most cases as a baseline to perhaps $8-10 \%$ as a high depending on the season, as animal food--which in their case includes bird's eggs and insects in addition to flesh--particularly insects, which are much more heavily consumed than is flesh. [62]

\section{Meat consumption by chimps}

There is considerable variation across different chimp populations in flesh consumption, which also fluctuates up and down considerably within populations on a seasonal basis as well. And behavior sometimes differs as well. Chimps in the Tai population, in 26 of 28 mammal kills, were observed to break open the bones with their teeth and use tools to extract the marrow for consumption, [63] reminiscent of early Homo habilis. One population has been observed to eat as much as $4 \mathrm{oz}$. of flesh per day during the peak hunting season, dwindling to virtually nothing much of the rest of the time, but when it is available, it is highly anticipated and prized. [64] It is hard to say exactly, but a reasonable estimate might be that on average flesh may account for about $1-3 \%$ of the chimp diet. [65]

\section{Significant role of social-insect, termite and ant consumption}

Meat consumption among chimps is what gets the headlines these days, [66] but the bulk of chimpanzees' animal food consumption actually comes in the form of social insects. [67] termites, ants, and bees, which constitute a much higher payoff for the labor invested to obtain them [68] than catching the colobus monkeys that are often the featured flesh item for chimps. However, insect consumption has often been virtually ignored [69] since it constitutes a severe blind spot for the Western world due to our cultural aversions and biases about it. And by no means is insect consumption an isolated occurrence among just some chimp populations. With very few exceptions, termites and/or ants are eaten about half the days out of a year on average, and during peak seasons are an almost daily item, constituting a significant staple food in the diet in terms of regularity, the remains of which show up in a minimum of approximately $25 \%$ of all chimpanzee stool samples. [70]

Miscellaneous items eaten by chimps include a few eggs, [71] plus the rare honey that chimps are known to rob from beehives as well as the embedded bees themselves, which is perhaps the most highly prized single item in their diet, [72] but which they are limited from eating much of by circumstances. Soil is also occasionally eaten presumably for the mineral content. [73]

\section{Other ape diets}

In order of how closely related the other great apes are to humans, the gorilla is next after the chimpanzee, then the orangutan, and gibbon in decreasing order. [76]

\section{Diet of gorillas compared with chimps}

While the gorilla has often been cited as a model in the modern mythology of fruitarianism, [77] on average it is actually the least frugivorous of the apes. Highland gorillas where less fruit is 
available in their higher-altitude mountainous habitat, have become primarily folivorous which means leaf-vegetative-eaters, while the lowland gorilla is more of a hybrid folivore/frugivore. [78] There is some suggestion chimps seem not to prefer extra-high roughage volumes, at least compared to the gorilla. Certainly they do not seem to be able to physiologically tolerate as much cellulose from vegetative matter in their diet. [79] Gorillas can tolerate higher amounts of folivorous matter, due apparently to their more varied and extensive intestinal flora and fauna. [80] Chimps, however, are known to wadge some of their foods, which is a form of juicing that has the effect of reducing their fiber intake. [81] Wadging means that they make a wad of leaves which is mixed in with the primary food item such as a fruit as a mass, which is then used as a press against their teeth and palate to literally juice the main food which they may suck on for up to 10 minutes before discarding the wadge of fiber after all the juice has been sucked out. Wadging may also serve as a way to avoid biting into potentially toxic seeds of certain fruits, from which they can then still extract the juices safely, or as a way to handle very soft items such as pulpy or overripe fruits, as well as eggs and meat. [82] Such behavior ought to debunk the prevalent Hygienic-raw-foods myth that it is always the more natural thing to do to eat whole rather than fragmented foods. This is not necessarily true, and again, such a view is based in subjective definitions out of touch with the real world. Another example is that chimps and gorillas as well, also eat a fair amount of pith in their diet--meaning the insides of stems of various plants which they first have to process by peeling off the tough outer covering before the pith inside is either eaten or wadged. [83]

\section{Other diet of apes less closely related to humans}

All the great apes, with the exception of the gorilla, are primarily frugivorous, but they do eat some animal products as well, though generally less than the chimp, although lowland gorillas eat insects at a comparable rate to chimps. In decreasing order of animal food consumption in the diet, the orang comes first after the chimp, then the bonobo chimp, the gibbon, the lowland gorilla, and the highland gorilla the latter eating any animal foods as insects incidentally in or on the plants eaten. Again, remember, animal food consumption here does not equate solely with flesh consumption, as that is less prominent than insects in ape diets. The chimp and bonobo chimp are the only ones to eat flesh other than a rare occurrence of an orang that was observed doing so once. All the apes other than the highland gorilla eat at least some social insects, with the chimp, bonobo chimp, and orang also partaking of bird's eggs. [84]

\section{Conclusions \& Recommendations}

This research which has gone deeply through the nutrition of the first primate till the modern human beings in the line of human evolution concludes that hunter gatherer diet was the safest diet which consists of high fat and medium protein. The Neolithic or the agricultural revolution which introduced grains and milk in the diet of humans is the time when many metabolic diseases, cancer and also infectious diseases became epidemic. Gluten and lactose intolerances were introduced in the human diseases and became epidemic. The height of humans decreased and the malnutrition rose. Animal Saturated fats were the staple of the hunter gatherer diets which has been demonized and the consumption of animal protein has decreased to some extent. Grains, soy and carbohydrate consumption has raised which due to adaptation to change time in human evolution, is not a healthy option. The diet after agricultural revolution which is high in 
carbohydrate and grains is the main cause of autoimmune diseases and cancer. Hunter gatherer diet which is high in animal saturated fat, cholesterol and medium animal protein which is like a ketogenic diet, is the safest bet in modern human diets and because the mentioned diseases in hunter gatherers were very rare, we can conclude that the ketogenic diet can be a prevention and cure for metabolic diseases including cancer.

\section{Acknowledgements}

I would like to thank Professor Stephanie Seneff Ph.D. Senior Research Scientist at Massachusetts Institute of Technology (MIT), Professor Thomas N. Seyfried Ph.D. Professor of Biology and Genetics, Boston College for their precious informative help, and Weston A. Price Foundation (WAPF) for its support in this research informatically and inspirationally.

\section{References}

[1] Eaton, Shostak, and Konner 1988a; Eaton, Shostak, and Konner 1988b, p. 69; Andrews and Martin 1992, p. 41; Foley 1995, p. 59.

[2] Andrews and Martin 1992, p. 41; Eaton, Shostak, and Konner 1988b, p. 70.

[3] Eaton, Shostak, and Konner 1988b, p. 70; Eaton, Shostak, and Konner 1988a.

[4] Eaton and Konner 1985, p. 284 (chart); Eaton, Shostak, and Konner 1988b, p. 20; Groves 1993, pp. 42-43.

[5] Groves 1993, pp. 42-43; Foley 1995, pp. 58, 70.

[6] Foley 1995, pp. 62-66; Thiessen 1996, p. 76.

[7] Eaton, Shostak, and Konner 1988b, p. 70; Foley 1995, p. 98.

[8] Foley 1995, pp. 70, 77, 83.

[9] Foley 1995, p. 71.

[10] Megarry 1995, pp. 169-172.

[11] Burenhult 1993c, p. 57.

[12] Megarry 1995, pp. 176-177.

[13] Walker 1996, pp. 147-149, 155; Sillen 1992, pp. 512-513.

[14] Megarry 1995, p. 232.

[15] Megarry 1995, p. 199; Blumenschine 1992, pp. 51-52; Rowley-Conwy 1993a, pp. 60-61.

[16] Burenhult 1993c, p. 62.

[17] Rowley-Conwy 1993a, pp. 60-61, for overview of the debate.

[18] Megarry 1995, p. 200.

[19] Walker 1996, p. 155.

[20] Burenhult 1993c, p. 62; Foley 1995, pp. 88-92.

[21] Burenhult 1993c, p. 63.

[22] Burenhult 1993c, p. 63.

[23] Burenhult 1993c, pp. 62-63.

[24] Scarre 1993, p. 38.

[25] Foley 1995, p. 88; Thiessen 1996, p. 100.

[26] Burenhult 1993c, p. 67; Scarre 1993, pp. 42-43, 48.

[27] Foley 1995, pp. 88, 124; Groves 1993, p. 49.

[28] Berglund and Björck 1993, pp. 82-83; Burenhult 1993d, p. 84.

[29] Scarre 1993, p. 41. Burenhult 1993d, pp. 80-81; Berglund and Björck 1993, pp. 82-83.

[30] Davidson and Noble 1993, p. 46.

[31] Goudsblom 1992, p. 1.

[32] Scarre 1993, p. 38; Eaton, Shostak, and Konner 1988b, p. 71. 
[33] Burenhult 1993c, p. 64.

[34] Scarre 1993, p. 54.

[35] Eaton and Konner 1985, p. 284; Eaton, Shostak, and Konner 1988b, p. 71; Scarre 1993.

[36] Eaton, Shostak, and Konner 1988b, p. 96.

[37] Eaton, Shostak, and Konner 1988b, pp. 2, 21, 40; Burenhult 1993d, p. 85; Scarre 1993, pp. 47, $52-53,55$.

[38] Eaton 1992, p. 817; Eaton, Shostak, and Konner 1988b, p. 75.

[39] Eaton and Konner 1985, p. 284; Eaton, Shostak, and Konner 1988b, p. 71.

[40] Berglund and Björck 1993, p. 82.

[41] Scarre 1993, p. 50.

[42] Scarre 1993, pp. 40, 50-51.

[43] Liljegren 1993, p. 86; Burenhult 1993d, pp. 84-85.

[44] Scarre 1993, pp. 54, 56.

[45] Scarre 1993, p. 50.

[46] Scarre 1993, p. 54.

[47] Burenhult 1993d, p. 81; Eaton, Shostak, and Konner 1988b, p. 73; Ulijaszek 1992, p. 112.

[48] Ulijaszek 1992, p. 112.

[49] Eaton, Shostak, and Konner 1988b, p. 71; Palmqvist 1993, pp. 18-20, 24; Burenhult 1993d, p. 81; Scarre 1993, pp. 56, 61; Ulijaszek 1992, p. 112.

[50] Goudsblom 1992, pp. 30-33, 44-47.

[51] Coursey 1975, p. 204.

[52] Coursey 1975, p. 203.

[53] Ulijaszek 1992, p. 112; Burenhult 1993d, pp. 92-93.

[54] Eaton, Shostak, and Konner 1988b, p. 25.

[55] Scarre 1993, pp. 61, 64.

[56] Palmqvist 1993, pp. 18-20, 24; Eaton, Shostak, and Konner 1988b, p. 25.

[57] Ulijaszek 1992, p. 112; Scarre 1993, pp. 66, 74.

[58] Eaton, Shostak, and Konner 1988b, p. 25.

[59] Eaton and Konner 1985, p. 286; Eaton, Shostak, and Konner 1988b, pp. 73, 80; Eaton et al 1996, p. 1733.

[60] Eaton and Konner 1985, p. 284; Eaton, Shostak, and Konner 1988b, p. 72.

[61] Ulijaszek 1992, p. 112.

[62] McGrew 1992, p. 154 (chart); Goodall 1986, p. 233 (chart).

[63] McGrew 1992, p. 117.

[64] Kopytoff 1995; Rensberger 1979.

[65] McGrew 1992, pp. 150-154; Tutin 1992; Wrangham 1992.

[66] Kopytoff 1995.

[67] Tutin 1992, pp. 20-21; McGrew 1992, pp. 153-154.

[68] McGrew 1992, p. 154.

[69] McGrew 1992, p. 209.

[70] McGrew 1992, p. 154; Goodall 1986, p. 248.

[71] Goodall 1986, pp. 232, 262.

[72] McGrew 1992, p. 145.

[73] Goodall 1986, pp. 246, 256.

[74] Goodall 1986, p. 246.

[75] Goodall 1986, p. 232.

[76] Groves 1993, pp. 42-43.

[77] Dinshah 1976-77, for interesting discussion.

[78] Tutin 1992, p. 19; McGrew 1992, pp. 43, 53.

[79] Tutin 1992, p. 23. 
[80] Tutin 1992, p. 23.

[81] Wrangham 1992, p. 18; Goodall 1986, p. 238.

[82] Goodall 1986, pp. 237-238.

[83] Goodall 1986, pp. 239-240.

[84] McGrew 1992, p. 44 (chart), 54 and following.

[85] Eldredge 1995, pp. 99-100.

[86] Eldredge 1995, p. 99.

[87] Cavalli-Sforza 1994, p. 12.

[88] Mogelonsky 1995.

[89] Simoons 1988, p. 87.

[90] Simoons 1988, p. 86.

[91] Simoons 1988, pp. 88-89.

[92] Simoons 1988, p. 83.

[93] Cavalli-Sforza 1994, p. 13.

[94] Mogelonsky 1995.

[95] Lutz 1995.

[96] Lutz 1995.

[97] Lutz 1995, p. 115.

[98] Lutz 1995, see charts on pages 116 and 117.

[99] Cavalli-Sforza 1994, p. 13.

[100] Cavalli-Sforza 1994, p. 13.

[101] Greco 1995.

[102] Hoggan, in press 1996/1997.

[103] Heng, Henry H. Q. (May 2009). "The genome-centric concept: resynthesis of evolutionary theory". BioEssays. Hoboken, NJ: John Wiley \& Sons. 31 (5): 512-525. doi:10.1002/bies.200800182. ISSN 0265-9247. PMID 19334004.

[104] Tyson, Peter (July 1, 2008). "Meet Your Ancestors". NOVA scienceNOW. PBS; WGBH Educational Foundation. Retrieved 2015-04-18.

[105] Dawkins 2004, "Find Time of Divergence: Hominidae versus Hylobatidae". TimeTree. Retrieved 2015-04-18.

[106] Ghosh, Pallab (March 4, 2015). "'First human' discovered in Ethiopia". BBC News. London: BBC. Retrieved 2015-04-19.

[107] Swisher, Curtis \& Lewin 2001

[108] Stringer 1994, p. 242

[109] McHenry 2009, p. 265

[110] Out of Africa Revisited. Science . Washington, D.C.: American Association for the Advancement of Science. 308 (5724): 921. May 13, 2005. doi:10.1126/science.308.5724.921g. ISSN 00368075.

[111] Stringer, Chris (June 12, 2003). "Human evolution: Out of Ethiopia". Nature. London: Nature Publishing Group. 423 (6941): 692-695. doi:10.1038/423692a. ISSN 0028-0836. PMID 12802315.

[112] Johanson, Donald (May 2001). "Origins of Modern Humans: Multiregional or Out of Africa?". actionbioscience. Washington, D.C.: American Institute of Biological Sciences. Retrieved 200911-23.

[113] Mixon, Bobbie; Ehardt, Carolyn; Hammer, Michael (September 6, 2011). "Evolution's Past Is Modern Human's Present" (Press release). National Science Foundation. Press Release 11-181. Retrieved 2015-04-20.

[114] O'Neil, Dennis. "Early Modern Homo sapiens". Evolution of Modern Humans: A Survey of the Biological and Cultural Evolution of Archaic and Modern Homo sapiens (Tutorial). San Marcos, CA: Palomar College. Retrieved 2015-04-20. 
[115] "Fossil Reanalysis Pushes Back Origin of Homo sapiens". Scientific American. Stuttgart: Georg von Holtzbrinck Publishing Group. February 17, 2005. ISSN 0036-8733. Retrieved 2015-04-20.

[116] Reich, David; Green, Richard E.; Kircher, Martin; et al. (December 23, 2010). "Genetic history of an archaic hominin group from Denisova Cave in Siberia". Nature.

[117] London: Nature Publishing Group. 468 (7327): 1053-1060. Bibcode:2010Natur.468.1053R. doi:10.1038/nature09710. ISSN 0028-0836. PMID 21179161.

[118] Noonan, James P. (May 2010). "Neanderthal genomics and the evolution of modern humans". Genome Research. Cold Spring Harbor, NY: Cold Spring Harbor Laboratory Press. 20 (5): 547553. doi:10.1101/gr.076000.108. ISSN 1088-9051. PMC 2860157. PMID 20439435.

[119] Abi-Rached, Laurent; Jobin, Matthew J.; Kulkarni, Subhash; et al. (October 7, 2011). "The Shaping of Modern Human Immune Systems by Multiregional Admixture with Archaic Humans". Science. Washington, D.C.: American Association for the Advancement of Science. 334 (6052): 89-94. Bibcode:2011Sci...334...89A. doi:10.1126/science.1209202. ISSN 00368075. PMC 3677943. PMID 21868630.

[120] Mellars, Paul (June 20, 2006). "Why did modern human populations disperse from Africa ca. 60,000 years ago? A new model". Proc. Natl. Acad. Sci. U.S.A. Washington, D.C.: National Academy of Sciences. 103 (25): 9381-9386. Bibcode:2006PNAS..103.9381M. doi:10.1073/pnas.0510792103. ISSN 0027-8424. PMC 1480416. PMID 16772383.

[121] Mcbrearty, Sally; Brooks, Alison S. (November 2000). "The revolution that wasn't: a new interpretation of the origin of modern human behavior". Journal of Human Evolution. Amsterdam, the Netherlands: Elsevier. 39 (5): 453-563. doi:10.1006/jhev.2000.0435. ISSN 00472484. PMID 11102266.

*Corresponding author.

E-mail address: saina.monthly@gmail.com 